longer be ignored. A placement such as this is time-efficient and provides many unique training opportunities. It is strongly recommended to all senior registrars interested in forensic adolescent psychiatry, and would also provide an important adjunct to any broad based training scheme for senior registrars in child and adolescent psychiatry.

REDER, P. \& LUCEY, C. (1990) Child and adolescent psychiatry training schemes: recent developments. Psychiatric Bulletin, 14, 615-617.

A. J. HiLl-Smrth, North West Thames Child Psychiatry Training Scheme, Adolescent Unit, Hill End Hospital, St Albans ALA ORB

\section{The experience of poychiatry in general practice trainees}

Sir: I would like to relate the findings of a study into the attitudes of general practice trainees who are completing a six month hospital training post in psychiatry. I feel the relevance of the training must be assessed due to recent changes in the organisation of the NHS and the increasing proportion of patients being cared for in the community. Indeed, Kendrick et al (1994) suggest that "General practitioners could use their frequent contacts with long-term mentally ill people to play a greater role in monitoring the mental state and drug treatment of this group".

In order to evaluate attitudes to training within the field of psychiatry, GP trainees were asked to complete a postal questionnaire during the last month of their placement, covering issues of formal teaching, supervision, and community experience. Completed questionnaires were received from 12 of the 16 trainees who completed hospital posts throughout the Mersey region between February and August 1994.

All trainees attended regular formal teaching sessions including a regional day release training course, and most trainees felt adequately supervised in all aspects of their placement.

Of particular note was trainees' general lack of knowledge of the community services available and uncertainty in the management of psychiatric patients in this setting. Over half of the trainees also felt that liaison with general practitioners was unsatisfactory with regard to referral of patients and their longterm follow-up care.
While only a small study I feel that it highlights some points of reference, particularly in view of the current changes in general practice. It is possible that experience should not merely include the acute hospital care of the in-patient, as is the case in many units at present, but should be broadened, enabling the trainee to gain a wider insight into care of the mentally ill in the primary care setting.

I feel that there may be a need for a reevaluation of some aspects of the training and that a more widespread survey of psychiatry for general practice trainees may also be appropriate.

Kendrick, T., Burns, T., Freelung, P. \& Sibbald, B. (1994) Provision of care to general practice in patients with disabling long-term mental illness: a survey in 16 practices. British Journal of General Practice. 44, 301305.

STEPHEN NoBlETt, Parkside Hospital, Macclesfield, Cheshire SK10 3JF

\section{Weather the whether?}

Sir: Man's emotional weather is as variable as the climate. Predictions about both are subject to error. Public reaction to these errors depend upon the subject. The British are resigned to being caught by the weather, whether or not they are forewarned. An unexpected shower is shrugged off, heavy snow or strong winds lead to inconvenience and grumbles, but rarely litigation, and even severe and possibly fatal events such as lightning strikes are accepted as acts of God, but then we cannot change the weather.

In spite of a massive data base and high technology, weather forecasting is probabilistic and its value limited to a few days by the 'chaos' of nature (Glieck, 1988; Palmer, 1992). What then of the psychiatrist's forecasts of human behaviour? His data may be limited and the technology low. Yet human intrapsychic and group behaviour is no less dynamic than the weather, and no less subject to the non-linear implications of 'chaos'. Even state of the art predictions in psychiatry are limited, and further diminish in value with forward projection. Like the weather, psychiatric problems vary from say a squall of verbal abuse, through a storm of physical violence (directed to self or others), to the 


\section{CORRESPONDENCE}

lightning cataclysm of homicide or suicide. Public reaction to such events may range from indifference in the face of minor local disturbances (although personal responses from those involved in the storm may cause climatic deterioration!), to condemnation, inquiry, and possibly litigation. When there is a storm about there is a public expectancy that the psychiatrist is a better forecaster than the weatherman.

Of course, psychiatrists, like weather forecasters must make every effort to improve their data base, theory and practice, but like meteorologists they will from time to time make genuine mistakes, only evident with the wisdom of hindsight. They may also make preventable errors for which they must bear responsibility, but overall the public, when judging psychiatrists, might well remember the weather, and consider:

Whether the weather be fine

Or whether the weather be not

We'll weather the weather

Whatever the weather

Whether we like it or not

GLECK, J. (1988) Chaos. London: Macdonald.

PALMER T. (1992) A weather eye on unpredictability. In The New Scientist Guide to Chaos. (ed. N. Hall) London: Penguin Books.

GORDON LANGLEY, Hanningfields, Warborough Hill, Kenton, Exeter, Devon EX6 8LR

'Lottomania'

Sir: I wish to describe the first case report, to my knowledge, of a delusional belief incorporating the National Lottery. The patient was seen shortly after the recent institution of the lottery.

A 58-year-old married woman was admitted to hospital after a two week history of illness. She had become concerned that she had won the lottery and because of this she and her family were being persecuted. She believed that her neighbours were trying to get this money and that she and various members of her family were at risk of great harm. The patient was agitated, restless and had been sleeping poorly. She displayed grandiose and persecutory delusions.

Following admission and the commencement of neuroleptic medication the symptoms resolved over the next three weeks, and at follow-up she has remained well.

I would wager this specific type of delusional belief is likely to become increasingly common given the current public and media preoccupation with the lottery. Might I venture to suggest the term 'lottomania'?

HARRY DOYLE, Harrow and Hillingdon Healthcare NHS Trust, Northwick Park Hospital, Harrow HA1 $3 U \mathrm{U}$ 